\title{
Respeto por la autonomía individual y el beneficio colectivo: argumentación a favor de la vacunación obligatoria contra el SARS-CoV-2 para el personal de la salud \\ Respect for individual autonomy and a collective benefit: Arguments in favor of compulsory SARS-CoV-2 vaccination among health care professionals
}

\section{Dr. Ezequiel Monteverde ${ }^{a}$}

\section{RESUMEN}

Con la llegada de las vacunas contra el SARS$\mathrm{CoV}-2$, un nuevo aspecto a tener en cuenta en la pandemia es el rechazo a la vacunación. Comola recepción de la vacuna, es voluntaria, se plantea cómo abordar la situación de los miembros del equipo de salud que la rechazan. Se exponen argumentos bioéticos de diversas corrientes: el deontologismo kantiano y lo conceptos de universalidad, humanidad y autonomía; el utilitarismo de Mill, con la autoprotección como único fin por el cual la humanidad está habilitada para interferir con la libertad de acción de sus miembros; el principismo de Beauchamp y Childress y los conceptos de beneficencia y autonomía; el principio de oportunidad de Varo la ética de los derechos humanos. Se incluyen aportes de filósofos contemporáneos como Roberto Espósito, Jean-Luc Nancy y Alberto Giubilini. Se exponen dos contrargumentos: el de no maleficencia y el de contraproducencia. Por último, se plantea que, dado que el bien común (la salud pública, en este caso) es el determinante íntimo y último de la libertad individual e igual para todos, está por encima del beneficio individual.

a. Unidad de Terapia Intensiva, Hospital de Niños Ricardo Gutiérrez; Fundación Trauma, director del sistema de registro.

Correspondencia:

Dr. Ezequiel

Monteverde:

ezequielmonteverde@ gmail.com

Financiamiento:

Ninguno.

Conflicto de intereses:

Ninguno que declarar.

Recibido: 21-1-2021

Aceptado: 18-3-2021

individual y el beneficio colectivo: argumentación a favor de la vacunación obligatoria contra el SARSCoV-2 para el personal de la salud. Arch Argent Pediatr 2021;119(4):e298-e302. Baena; y el principio de solidaridad, derivado de

\section{INTRODUCCIÓN}

Un aspecto relacionado con la pandemia por la enfermedad del nuevo coronavirus (COVID-19) y una de las vías de solución con las que el mundo cuenta -la vacunación masiva- llenó las páginas de los medios masivos de difusión a partir de las primeras aprobaciones de vacunas por agencias regulatorias. De manera contraintuitiva, luego de un año de restricciones y pérdidas de recursos humanos para todo el equipo de salud, esta intervención, considerada una solución posible, en algunos lugares del mundo está siendo resistida. ${ }^{1-4}$ Hasta el momento, la vacunación es un acto voluntario en todos los países. Surge, entonces, el planteo de cómo manejar el rechazo de la vacunación entre aquellos que pertenecen, por ejemplo, a grupos de personas (profesionales de la salud o no) que se desempeñan en ámbitos ligados a la salud (hospitales, laboratorios, centros de diagnóstico por imagen) o en instituciones de cuidado de personas mayores, como residencias geriátricas. ¿Debería haber regímenes diferentes para distintos ciudadanos, según sus roles?

\section{Los aportes clásicos de la bioética}

Algunas respuestas pueden ensayarse desde las doctrinas clásicas de la bioética, deontológicas (Kant) y teleológicas (Mill) o desde la teoría de los principios (Beauchamp y Childress). El imperativo categórico 
kantiano se presenta en tres formulaciones que constituyen el núcleo de su filosofía ética: la universalidad (obrar según máximas que puedan aplicarse a todos por igual), la humanidad (las personas como un fin en sí y nunca como un medio) y la autonomía (actuar según máximas que las personas puedan elegir de manera autónoma). ${ }^{5}$ El planteo de la posibilidad de oponerse a la vacunación bajo la formulación de la universalidad solo sería tolerable en un mundo en el cual todos se opusieran a las vacunas. Esto contradice la opinión mayoritaria actual y el estándar de prevención desde hace décadas en la gran mayoría de los países. Si se planteara que algunos se vacunaran y otros, no (estos últimos, conocidos como "aquellos que reciben los beneficios de un bien colectivo sin contribuir a su producción" o free riders) ${ }^{6}$ se estaría usando a los vacunados como un medio para lograr la inmunidad de rebaño y proteger a los no vacunados, lo cual también sería inaceptable. Con respecto a la autonomía, es el aspecto más controvertido porque, en la vida en comunidad, cada uno debería contribuir con su parte (el munus, tributo que cada miembro de una comunidad debía rendir para sostener su pertenencia) para lograr el bien común, y esa decisión podría ir en contra de creencias individuales. ${ }^{7}$ Una persona libertaria podría plantear que el objeto del imperativo categórico pueda ser el respeto por la decisión individual, con lo que se cumplen la primera formulación (cada uno decide su propio régimen vacunal), la segunda (respeto de la voluntad de cada persona en virtud de que un rechazo masivo le resulta tolerable) y la tercera, porque estas decisiones se dan en uso de plena autonomía de cada uno. En vista de lo expuesto, se plantea si no es la salud un objeto a perseguir siempre en forma común, si existe la posibilidad de salud individual plena en un contexto comunitario insalubre, y qué sucede con los sujetos que, por su edad o por condiciones de salud (enfermedad activa, comorbilidades) tienen contraindicación de vacunarse, pero que se beneficiarían de la inmunidad de rebaño transferida por los vacunados. Según Aristóteles, el ser humano es un animal político, "el hombre es por naturaleza un animal social, y ...por naturaleza, pues, la ciudad es anterior a la casa y a cada uno de nosotros, porque el todo es necesariamente anterior a la parte" ${ }^{8}$ Con base en esta afirmación, ¿no estamos cada uno de nosotros obligados a brindar ese munus a los fines de sostener la estructura mínima de la comunidad?

Por otro lado, el principio del daño de John S. Mill, que afirmó que "la única razón para restringir la acción de un individuo es prevenir el daño a otros", sirve también para pensar el problema desde otro punto de vista, en virtud de que este principio es uno de los pilares del liberalismo clásico. ${ }^{9}$ Se suele pensar que el objetivo central del liberalismo es la protección y la promoción de la autonomía individual, y a menudo se invoca a Mill como uno de sus defensores. Si bien es cierto que para Mill la autonomía individual no era negociable, lo que promovía era un progreso social motorizado por el individuo y entendía que este último era el verdadero generador de los cambios requeridos. ${ }^{10}$ Así, el principio del daño servía a los fines de equilibrar el progreso social impulsado por individuos con el orden social. Dice Mill en su obra Sobre la libertad: "El objeto de este ensayo es afirmar un principio muy simple, que tiene la finalidad de gobernar el contrato de la sociedad con el individuo en forma de coacción y control, a través de sanciones legales, o de la coerción moral de la opinión pública. Ese principio es que el único fin por el cual la humanidad está habilitada, individual o colectivamente, para interferir con la libertad de acción de cualquiera de sus miembros, es la autoprotección. El único propósito para ejercer el poder legítimamente sobre cualquier miembro de una comunidad civilizada, en contra de su voluntad, es prevenir daños a otros. (...) Si alguien lleva a cabo un acto que daña a otros, hay una justificación prima facie para castigarlo, por ley, o, cuando las sanciones legales no son aplicables con seguridad, por desaprobación general". ${ }^{11}$

En relación a la bioética de los principios de Beauchamp y Childress, es fácil encontrar la beneficencia si se acuerda que no existe medida de salud pública que haya beneficiado tanto a la humanidad como la mejora en el acceso al agua y alimentos y las vacunas. ${ }^{12}$ Con respecto al principio de no maleficencia, puede verse afectado al considerar a aquellos que podrían resultar dañados; pero ¿qué intervención terapéutica, preventiva o diagnóstica está libre de riesgos? Ninguna. Por este motivo, levantar este argumento contra las vacunas es levantarlo contra la medicina en su totalidad, y así debería abordarse el problema. Con certeza, la justicia es el principio más vulnerado en este momento, ya que con la información actual se puede asegurar de que no habrá un acceso 
equitativo a la inmunización. ${ }^{13}$ Con respecto al principio de autonomía (principio de respeto por la autonomía, diría Childress), desde la misma ética principista se plantea que puede ser sobrepasado o infringido cuando se cumplen las condiciones de proporcionalidad (principios competitivos más fuertes), efectividad (infringir el principio de autonomía protege los principios con los cuales compite), último recurso (necesidad de proteger los principios con los cuales compite) y transgresión menor (ser la menos intrusiva o restrictiva en circunstancias específicas). ${ }^{14,15} \mathrm{~A}$ estos cuatro principios, Varo Baena ${ }^{16}$ se permite agregar un quinto, de especial relevancia en este momento y para la pregunta planteada en este texto: el principio de oportunidad. Este concepto se refiere al planteo de si existe una responsabilidad moral de inmunizar en un momento definido y en determinadas condiciones colectivas y sociales. Si se tiene en cuenta que la misma intervención realizada en dos momentos históricos diferentes tendría consecuencias distintas, queda claro que la consideración no solo tiene aspectos operativos, sino también éticos. La carrera por la aprobación rápida de las vacunas es testimonio de ello.

\section{¿Qué plantean algunos contemporáneos?}

Jean-Luc Nancy recupera a Karl Marx para el análisis de la tensión actual entre la autonomía individual y la beneficencia colectiva. En términos marxistas, la autonomía no existe, o existe para unos pocos, ya que el sujeto se encuentra enajenado. Por eso, el planteo de individuo versus comunidad es falso, dado que los supuestos beneficios del punto de vista individual no son tales, porque no están disponibles. Esa distorsión de la percepción, en la cual un sujeto se asume libre, autónomo y capaz de elegir por sí mismo, está generada por el mismo sistema que enajena y por esto, paradójicamente, quienes proclaman la libertad individual son los más férreos defensores del sistema que los expropia de su ser. ${ }^{17}$ Por ejemplo, cuando no se tiene acceso al agua potable, ¿cómo hacer para lavarse las manos con frecuencia? ${ }^{18}$ Dice Nancy: "Lo propio del individuo es ser incomparable, inconmensurable e inasimilable, inclusive a sí mismo. No es poseer bienes, es ser una posibilidad de realización única, exclusiva y cuya unicidad exclusiva, por definición, no se realiza sino entre todos y con todos; contra todos o a pesar de todos igualmente pero siempre en la relación y el intercambio (la comunicación)" ${ }^{19}$ La pandemia puso en jaque nuestra autonomía, nos reveló interconectados, y puso la lupa sobre los aspectos relacionales que brindan una idea falsa de autonomía. La ausencia de autonomía revela la necesidad que tenemos de apoyarnos en los otros para lograr nuestros objetivos, y ¿de qué manera lo hacemos?, ¿existe forma de apoyarnos entre todos sobre una base de igualdad?, ¿existe una distribución de recursos que nos permita reconocernos como iguales? Claramente no, cuando vemos la distribución de las primeras dosis de vacunas. ${ }^{13}$ Roberto Espósito, filósofo italiano cuya obra puede clasificarse dentro de la biopolítica, analizó las relaciones entre los conceptos de "comunidad" (política) e "inmunidad" (médico-epidemiológico). Ambos comparten la raíz munus: la comunidad es, entonces, un grupo humano unido por una ley y una obligación común, pero también por una ofrenda (cada uno de los individuos ofrenda su parte para construir el bien común, que luego sirve como principio ordenador). Del otro lado, la inmunidad era el privilegio que se confería a ciertos miembros de la comunidad de no tener que aportar el munus, figura que todavía persiste, por ejemplo, en la inmunidad parlamentaria o diplomática. ${ }^{20}$ Así, alrededor de esta obligación y ofrenda se estructura la comunidad.

Con base también en la línea deontológica, Alberto Giubilini desafía el argumento del daño a terceros y propone una analogía entre el rechazo de la vacunación y la evasión impositiva, y recurre a un fragmento de Sobre la libertad: “... cada uno que recibe protección de parte de la sociedad debe retornar el beneficio y (...) es indispensable que cada uno observe una cierta línea de conducta hacia el resto. Esto implica no dañar los intereses de otros y (...) el aporte de cada persona (cuya magnitud debería fijarse en base a principios equitativos) en forma de trabajo y sacrificio para defender a la sociedad $\mathrm{o}$ a sus miembros de lesiones y pesares" ${ }^{11} \mathrm{O}$ sea que, dado que es poco probable que el aporte individual de una persona logre incidir en el conjunto, más allá de hacer un daño o dejar de hacer un bien a otros, la incorporación de trabajo y sacrificio se basa en una noción de equidad; es decir, es lo que nos corresponde en tanto partes de un todo. ${ }^{21}$ Para esto existen justificaciones morales (un pequeño esfuerzo de cada uno para el logro de un bien colectivo de gran valor) pero también legales (en la medida que los bienes en juego son relevantes para la sociedad, se justifica la aplicación de estrategias jurídicas para obtenerlos). Como sucede con el pago de 
impuestos, es obligación del Estado asegurar la equidad de la vacunación: el deber individual de contribuir se refuerza de manera positiva en la medida que más individuos se incorporan a la campaña compulsiva de vacunación.

\section{Dos argumentos a considerar}

Si bien podría cuestionarse la vacunación compulsiva bajo el principio de no maleficencia en virtud de que, en la actualidad, las vacunas se aprueban sin haber finalizado la fase III de los ensayos y con un tiempo de seguimiento insuficiente para documentar eventos adversos en el mediano o en el largo plazo, este argumento se basa en dos supuestos falsos. Por un lado, asume que el único riesgo para la salud es el de presentar efectos adversos por la vacuna, y omite el riesgo derivado de contraer la infección por el virus. Por otra parte, cabe preguntarse cuál es el costo de la infección a terceros a partir de un individuo que decidió no vacunarse, y qué ocurriría si esa persona tuviera contacto (laboral, social, etc.) con sujetos con riesgo incrementado de desarrollar formas clínicas graves. En algunos países como Estados Unidos, proponer el uso obligatorio de vacunas contra el SARS-CoV-2 bajo una autorización de emergencia es problemático tanto desde el punto de vista legal como ético, dado que este tipo de autorizaciones tiene requerimientos de seguridad y eficacia más bajos que una aprobación completa. ${ }^{22}$ Sin embargo, la Ley 27491 dice en su artículo 7 que apoya la condición de obligatoriedad cuando exista "una situación de emergencia epidemiológica". ${ }^{23}$

Otro argumento en contra de la vacunación compulsiva es que podría resultar una medida contraproducente. Bajo el supuesto de que, si la vacuna es tan buena, todos querrían aplicársela y no habría necesidad de hacerla obligatoria, se pretende persuadir a la población de que toda medida obligatoria será siempre rechazada. Más aún, hay quienes argumentan que es probable que las personas desconfíen de la obligatoriedad de vacunas aprobadas bajo uso de emergencia, y la consideren una investigación médica encubierta. ${ }^{22}$ Sin embargo, experiencias como la de Italia y Francia en relación con las campañas con la vacuna triple viral luego de experimentar incrementos significativos de los casos de sarampión, desmienten este argumento, ${ }^{24,25} \sin$ perder de vista que, dada la heterogeneidad ética y cultural entre países, no existe una solución única que aplique a todos. ${ }^{26}$

\section{CONCLUSIÓN}

En el planteo clásico de libertad individual versus beneficio colectivo, reactualizado en este contexto de pandemia, siempre hay una pérdida de la libertad (en tanto se la defina como la capacidad de no actuar sino según la propia decisión), ${ }^{19}$ cualquiera sea la intervención considerada. Según esta definición, la libertad y el respeto por la autonomía ${ }^{14}$ son categorías equivalentes. Lo que me permito opinar es que la defensa de una libertad individual plena, sin límites, es un enfoque demasiado ingenuo como para ser considerado. Ninguna filosofía ni teología de la modernidad atribuyó al sujeto la libertad como un poder de autodeterminación liso y llano. ${ }^{19} \mathrm{El}$ determinante íntimo y último de la libertad individual es que es igual para todos: todos los seres humanos somos idéntica e igualmente libres $y$, en tanto continuemos viviendo en aglomeraciones urbanas (polis), nos encontraremos en la confluencia entre la formulación universalista de la ética kantiana (el uso del barbijo es muy claro a este respecto) y el punto de vista utilitarista. Esto se debe a que, al actuar de esta manera, se lograría maximizar los beneficios como la menor cantidad de personas infectadas, menos enfermos graves y menos muertos atribuibles a esta causa.

Con respecto a los integrantes del equipo de salud, cabe pensar si es razonable aplicar sanciones a profesionales que no se vacunen o que difundan información falsa sobre vacunas. ${ }^{27}$ En este punto, es preciso detenerse en dos enfoques. Por un lado, siguiendo a Espósito, planteo que, si bien la asignación de la inmunidad a ciertos miembros de la comunidad siempre estuvo influenciada por la matriz de poder de cada lugar y época, en esta oportunidad debería transferirse a aquellas personas con contraindicaciones para vacunarse. Por otra parte, dado que estas personas requieren más intervenciones asistenciales, es lícito preguntarse quién, si no los miembros del equipo de salud, debería brindarle ese "privilegio" a través de un contacto seguro con profesionales inmunizados. En segundo lugar, este mismo concepto concurre con el principio de solidaridad relacionado con la bioética de los derechos humanos, a partir de las derivaciones de la Declaración Universal sobre Bioética y Derechos Humanos de la Organización de las Naciones Unidas para la Educación, la Ciencia y la Cultura: ${ }^{28}$ la solidaridad, junto con la cooperación, son la clave para el logro de los niveles más altos de salud, con especial 
consideración por los grupos vulnerables.

La bioética de la vacunación, como se mencionó, sintetiza el deontologismo kantiano con la ética utilitarista. Más aún, ese reconocimiento se encuentra también en la ley argentina a través del valor que le otorga a la salud pública por sobre el interés particular, sobre todo en una situación de emergencia epidemiológica en sus artículos 2 (inciso C) y 7. ${ }^{23}$ Por último, en este contexto no es posible aplicar la política del último recurso, ${ }^{29}$ dado que el nivel de incertidumbre es demasiado alto y que suscribir a esa línea llevaría a incumplir el argumento de oportunidad. En momentos en los que la realidad se modifica de manera permanente (un koinos kosmos o universo común prácticamente imposible), en el contexto de noticias falsas que alcanzan altísimos niveles de difusión y de artículos científicos desmentidos luego de ser publicados en las revistas con mayor prestigio, entiendo que es responsabilidad de nosotros, como miembros del equipo de salud, dar ese ejemplo.

\section{REFERENCIAS}

1. Coronavirus en EE.UU.: con casi 300.000 casos nuevos en un día, crece el rechazo de médicos y enfermeros a la vacuna. Clarín. Buenos Aires. 3 de enero de 2021. [Acceso: 14 de enero de 2021]. Disponible en: https: / / www.clarin.com/ mundo/vacuna-crece-rebelion-personal-salud-unidospese-avance-coronavirus_0_ZCtRYS-fb.html.

2. Facebook, Twitter, options S more sharing, LinkedIn, et al. Some healthcare workers refuse to take COVID-19 vaccine, even with priority access. Los Angeles Times 2020. California. Dic 31, 2020. [Acceso: 14 de enero de 2021]. Disponible en: https: / / www.latimes.com/california / story / 2020-12-31/ healthcare-workers-refuse-covid-19vaccine-access.

3. Zas Marcos M. Sanidad registrará las razones de quienes se nieguen a ponerse la vacuna contra la COVID-19. ElDiario.es. Madrid. 21 de diciembre de 2020. [Acceso: 14 de enero de 2021]. Disponible en: https: / / www.eldiario. es/sociedad/sanidad-registrara-razones-rechazo-vacunacovid-19_1_6521846.html.

4. Pinault $\bar{N}$. Francia se enfrenta al rechazo de la población a la vacuna contra el COVID-19. Voice of America. 30 de noviembre de2020. [Acceso:14 deenero de 2021]. Disponible en: https: / / www.voanoticias.com/ coronavirus / franciaresistencia-publica-vacuna-contra-covid19.

5. Kant I. La autonomía de la voluntad como principio supremo de la moralidad. En: Kant I. Fundamentación para una metafísica de las costumbres. 5ta reimp. Madrid: Alianza; 2019:157-8.

6. Hardin R, Cullity G. The Free Rider Problem. In: Zalta EN (ed). The Stanford Encyclopedia of Philosophy. Winter 2020 ed. Stanford: Metaphysics Research Lab, Stanford University; 2020.

7. Rivera Castro F. El imperativo categórico en la Fundamentación de la Metafísica de las Costumbres. Rev Digit Univ. 2004; 5(11):83.

8. Aristóteles.LibroI.En: Aristóteles.Política. Madrid:Gredos; 1988.Págs.50-1.

9. Taylor JS. The Harm Principle. Libertarianism.org. Washington DC. Jun 21, 2011. [Acceso: 17 de enero de
2021]. Disponible en: https://www.libertarianism.org/ media/around-web/harm-principle.

10. Yaylali M. El principio del daño: El equilibrio del progreso social en la filosofía política de John Stuart Mill. Foro Interno. 2019; 19:77-92.

11. Mill JS. On Liberty. In Mill JS. On liberty, utilitarianism, and other essays. $2^{\text {nd }}$ ed. New York: Oxford University Press; 2015; 14,65-6.

12. Greenwood B. The contribution of vaccination to global health: past, present and future. Philos Trans $R$ Soc Lond B Biol Sci. 2014; 369(1645):20130433.

13. VOA News. $95 \%$ of World's Vaccines Being Administered in 10 Countries, WHO Official Says. Voice of America January 14, 2021. [Acceso: 17 de enero de 2021]. Disponible en: https: / / www.voanews.com/ covid-19-pandemic/95worlds-vaccines-being-administered-10-countries-whoofficial-says.

14. Childress JF. El lugar de la Autonomía en la Bioética. En: Luna F, Salles ALF. Bioética: investigación, muerte, procreación y otros temas de ética aplicada. 2da ed. Buenos Aires: Sudamericana; 2000:Págs.133-44.

15. Childress JF, Faden RR, Gaare RD, Gostin LO, et al. Public health ethics: mapping the terrain. J Law Med Ethics. 2002; 30(2):170-8.

16. Varo Baena A. Vaccine bioethics and publichealth. Vacunas (English Edition). 2020; 21(1):57-63.

17. Marx K. El trabajo enajenado. En: Marx K. Manuscritos de economía y filosofía. Madrid: Alianza; 2003.Págs.104-20.

18. Vera F, Adler V, Uribe MC (eds). ¿Qué podemos hacer para responder al COVID-19 en la ciudad informal? Banco Interamericano de Desarrollo; 2020. [Acceso: 19 de enero de 2021]. Disponible en:https://publications.iadb.org/ es / que-podemos-hacer-para-responder-al-covid-19-enla-ciudad-informal.

19. Nancy JL. Un virus demasiado humano. Adrogué: La Cebra; 2020.

20. Espósito R. Immunitas. Protección y Negación de la Vida. Buenos Aires: Amorrortu; 2005.

21. Giubilini A. An Argument for Compulsory Vaccination: The Taxation Analogy. J Appl Philos. 2020; 37(3):446-66.

22. Gostin LO, Salmon DA, Larson HJ. Mandating COVID-19 Vaccines. JAMA. 2021; 325(6):532-3.

23. Ley 27491. Control de enfermedades prevenibles por vacunación. Buenos Aires, Argentina. 4 de enero de 2019. [Acceso:19 de enero de 2021]. Disponibleen:https: / / www. argentina.gob.ar/normativa/nacional/ley-27491-318455.

24. D'Ancona F, D'Amario C, Maraglino F, Rezza G, et al. Introduction of new and reinforcement of existing compulsory vaccinations in Italy: first evaluation of the impact on vaccination coverage in 2017. Euro Surveill. 2018; 23(22):1800238.

25. Lévy-Bruhl D, Fonteneau L, Vaux S, Barret A-S, et al. Assessment of the impact of the extension of vaccination mandates on vaccine coverage after 1 year, France, 2019. Euro Surveill. 2019; 24(26):1900301.

26. Drew L. The case for mandatory vaccination. Nature. 2019; 575:S58-60.

27. Güel O, García A. Inhabilitada una pediatra por propagar que las vacunas causan el autismo. EL PAÍS. Barcelona/ Madrid. 21 de junio de 2019. [Acceso: 18 de enero de 2021]. Disponibleen: https: / / elpais.com/sociedad/2019/06/20/ actualidad/1561034181_540468.html.

28. UNESCO. Declaración universal sobre Bioética y Derechos Humanos. 2005. [Acceso: 19 de enero de 2021]. Disponibleen:http:/ / portal.unesco.org/es/ev.php-URL

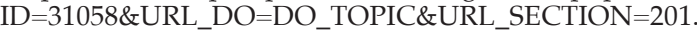
html.

29. Moorthy G. Compulsory COVID-19 Vaccination? Only as a Policy of Last Resort. VIB. 2020;6. [Acceso: 19 de enero de2021]. Disponibleen: https:/ / journals.library.columbia. edu/index.php/bioethics/article/view/7301. 